\title{
Influence of CYP1A2 and CYP2C19 polymorphisms on clozapine exposure in Tunisians schizophrenic patients
}

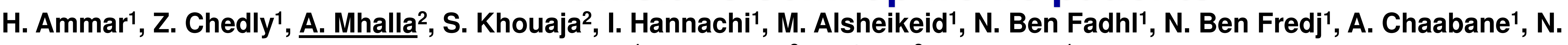
Boughattas', L. Zarrouk', L. Gaha'², K. Aouam'.

'Faculty of Medicine of Monastir- University of Monastir, Department of pharmacology, Monastir, Tunisia.

${ }^{2}$ Fatttouma Bourguiba Hospital, Department of Psychiatry, Monastir, Tunisia.

\section{Introduction}

* Clozapine : Resistant schizophrenia +++

- Interindividual variability \& narrow therapeutic index $\rightarrow$ Therapeutic Drug Monitoring (TDM)+++

CYP1A2 \& CYP2C19 : mainly responsible for the metabolism of clozapine

* Activity of these enzymes : several Single Nucleotide Polymorphisms (SNPs) $\rightarrow$ Interethnic variability

$\rightarrow$ Study allele and genotype frequencies of CYP1A2 \& CYP2C19 polymorphisms (SNPs) in Tunisian schizophrenic patients receiving clozapine and compare them with those of healthy volunteers

$\rightarrow$ Study the impact of CYP1A2 \& CYP2C19 on clozapine pharmacokinetics .

\section{Patients \& Methods}

* Cross sectional study : Pharmacology Department \& Psychiatry Department of University hospital center of Monastir * Schizophrenic patients receiving clozapine

* Clozapine dosing : High-performance liquid chromatography (HPLC)

* Trough concentration: C0(Therapeutic range(TR)) : 350 et $600 \mathrm{ng} / \mathrm{ml}$ )

*enotyping CYP1A2 \& CYP2C19 : PCR-RFLP

* SNPs : CYP1A2*1F - CYP1A2*1C - CYP2C19*2

* 25 patients \& 50 healthy subjects (HS) : included.

* Characteristics of the study population : Table II : Characteristics of patients Demographic Characteristics Mean \pm Standard deviation (extremes)

Age (years) $33,2 \pm 7,1(23-48)$

Weight (Kg) $80 \pm 12,3(50-115)$

Sex ratio : $\mathbf{M} / \mathbf{F}$ $5,25(21 / 4)$

* Comparaison of allelic repartition between patients \& HS :

Table III : Comparaison of allelic repartition between patients \& $\mathrm{HS}$

\begin{tabular}{|c|c|c|c|c|}
\hline \multirow{2}{*}{ SNP } & \multirow{2}{*}{ Allele } & \multicolumn{2}{|c|}{ Frequency } & \multirow{2}{*}{$\mathbf{P}$} \\
\hline & & Patients & HS & \\
\hline \multirow{2}{*}{$C Y P 1 A 2=1 F$} & C & $42 \%$ & $38 \%$ & \multirow{2}{*}{0,93} \\
\hline & A & $58 \%$ & $62 \%$ & \\
\hline \multirow{2}{*}{$C Y P 1 A 2=1 C$} & G & $96 \%$ & $96 \%$ & \multirow{2}{*}{1} \\
\hline & A & $4 \%$ & $4 \%$ & \\
\hline \multirow{2}{*}{$\mathrm{CYP} 2 \mathrm{C19} 2$} & G & $88 \%$ & $84 \%$ & \multirow{2}{*}{0,9} \\
\hline & A & $12 \%$ & $16 \%$ & \\
\hline
\end{tabular}

* Repartition of the trough concentration of clozapine:

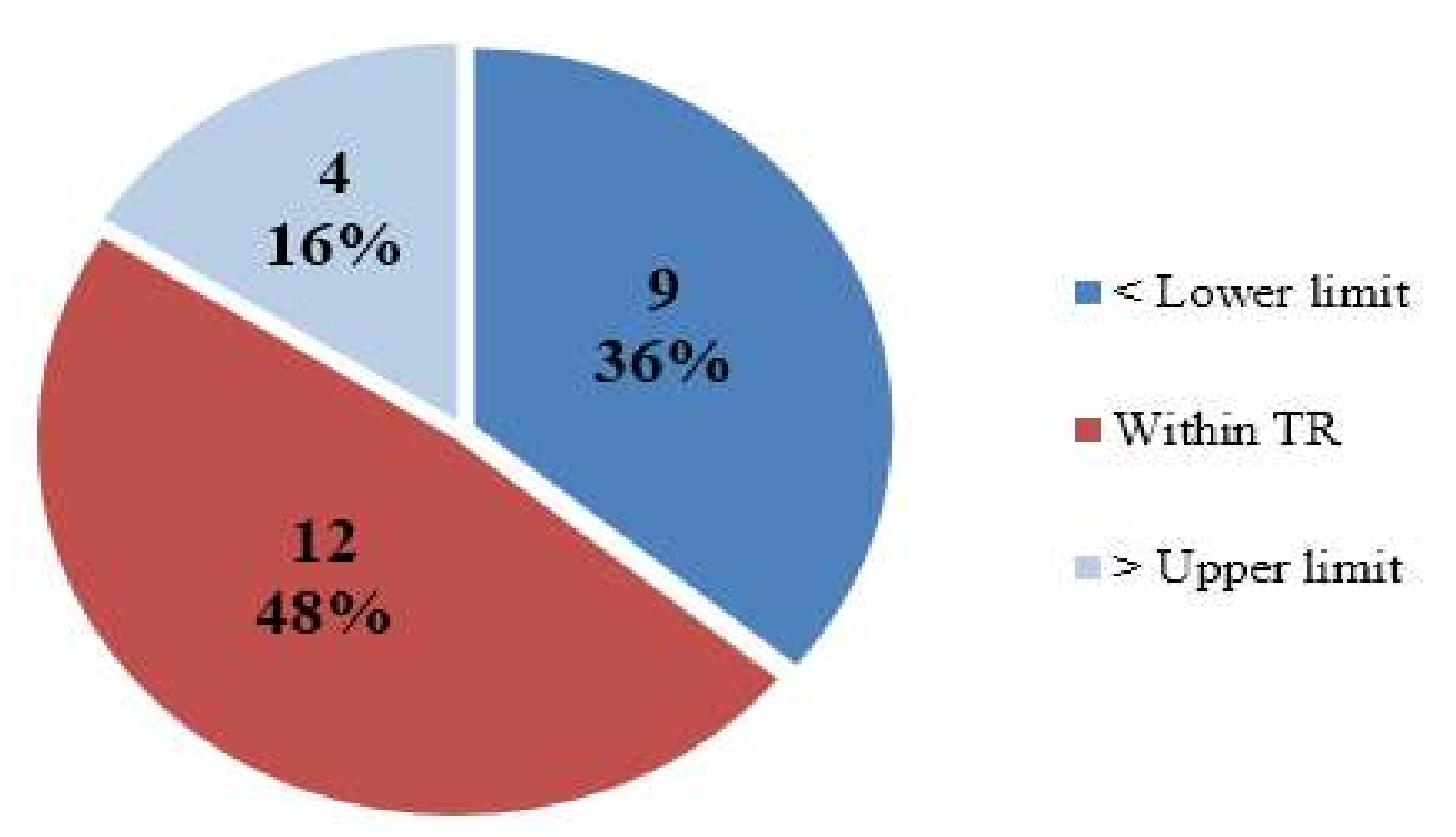

Figure 1 : Repartition of the trough concentration of clozapine

* Phenotypic repartition of the studied population:

Table IV : Phenotypic repartition of the studied population

\begin{tabular}{|c|c|c|}
\hline Phenotypic groups & Genotype combination & $\begin{array}{c}\text { Number } \\
\text { (percentage) }\end{array}$ \\
\hline Poor Metabolizers (PM) & $\begin{array}{c}C Y P I A 2 * I C(\mathrm{GA}) \\
+ \\
\left.C Y P 1 A 2 *^{*} \text { (CA or } \mathrm{AA}\right)\end{array}$ & $\begin{array}{c}2 \\
(8 \%)\end{array}$ \\
\hline $\begin{array}{l}\text { Intermediate Metabolizer } \\
\text { (IM) }\end{array}$ & $\begin{array}{c}C Y P 1 A 2 * 1 C(\mathrm{GG}) \\
+ \\
C Y P 1 A 2 * 1 F(\mathrm{CC})\end{array}$ & $\begin{array}{c}5 \\
(20 \%)\end{array}$ \\
\hline $\begin{array}{l}\text { Extensive Metabolizer } \\
\text { (EM) }\end{array}$ & $\begin{array}{c}C Y P I A 2^{*} I C(\mathrm{GG}) \\
+ \\
C Y P I A 2^{*} \text { (CA or AA) }\end{array}$ & $\begin{array}{c}18 \\
(72 \%)\end{array}$ \\
\hline
\end{tabular}

D CYP1A2*1F \& CYP1A2*1C: Controversial subject

- Meta-analysis (August 2018) ${ }^{1}$ :

CYP1A2*1F: absence of impact

CYP1A2*1C: non conclusive
Phenotypic study : Genotype combination of CYP1A2 \& CYP2C19 Table I : Phenotypic repartition of the studied population

\begin{tabular}{|c|c|}
\hline Phenotype & Genotype combination \\
\hline Poor Metabolizers (PM) & $\begin{array}{c}C Y P 1 A 2 * I C(\mathrm{GA} \text { or } \mathrm{AA}) \\
+ \\
C Y P 1 A 2 * I F(\mathrm{CC} \text { or } \mathrm{CA} \text { or } \mathrm{AA})\end{array}$ \\
\hline Intermediate Metabolizer (IM) & $\begin{array}{c}C Y P I A 2{ }^{*} I C(\mathrm{GG}) \\
+ \\
C Y P I A 2{ }^{*}{ }_{I F}(\mathrm{CC})\end{array}$ \\
\hline Extensive Metabolizer (EM) & $\begin{array}{c}\text { CYPIA2*IC (GG) } \\
+ \\
C Y P 1 A 2 * 1 F(\mathrm{CA} \text { or } \mathrm{AA})\end{array}$ \\
\hline
\end{tabular}

\section{Results}

- Impact of SNPs studied on pharmacokinetic (PK) of clozapine :

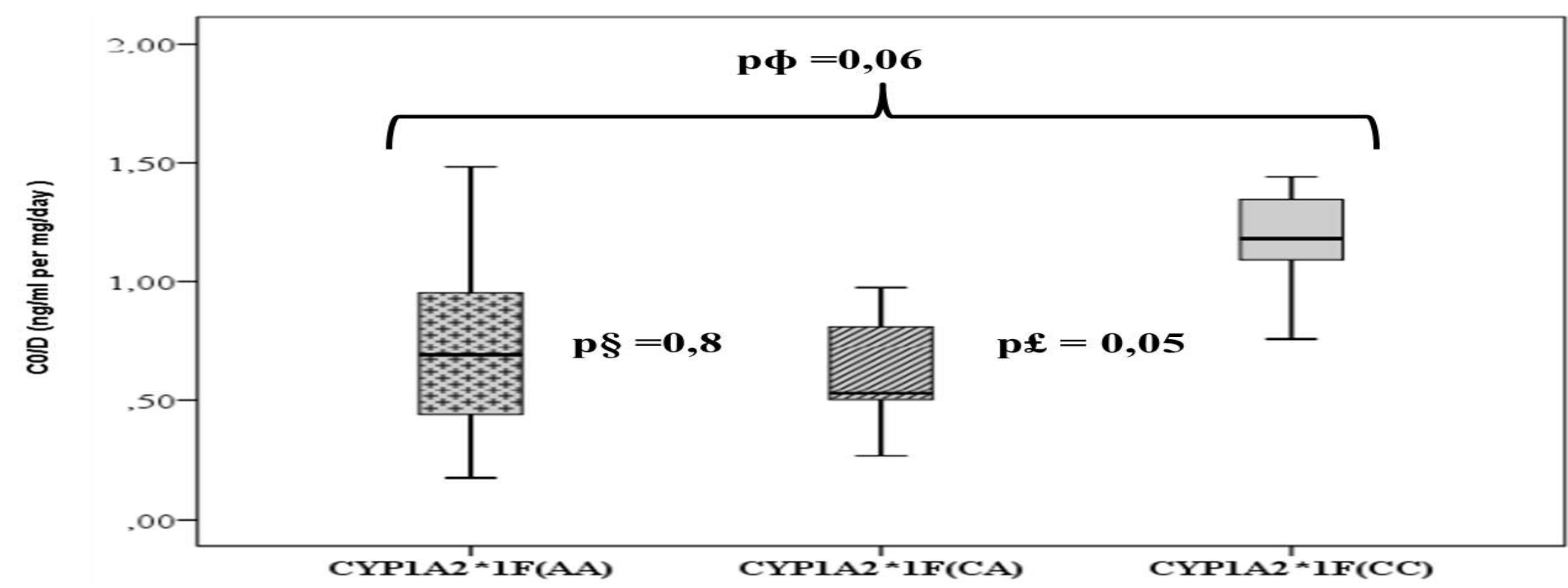

Figure 2 : The variation of CO/D ratio according to CYP1A2*1F genotypes

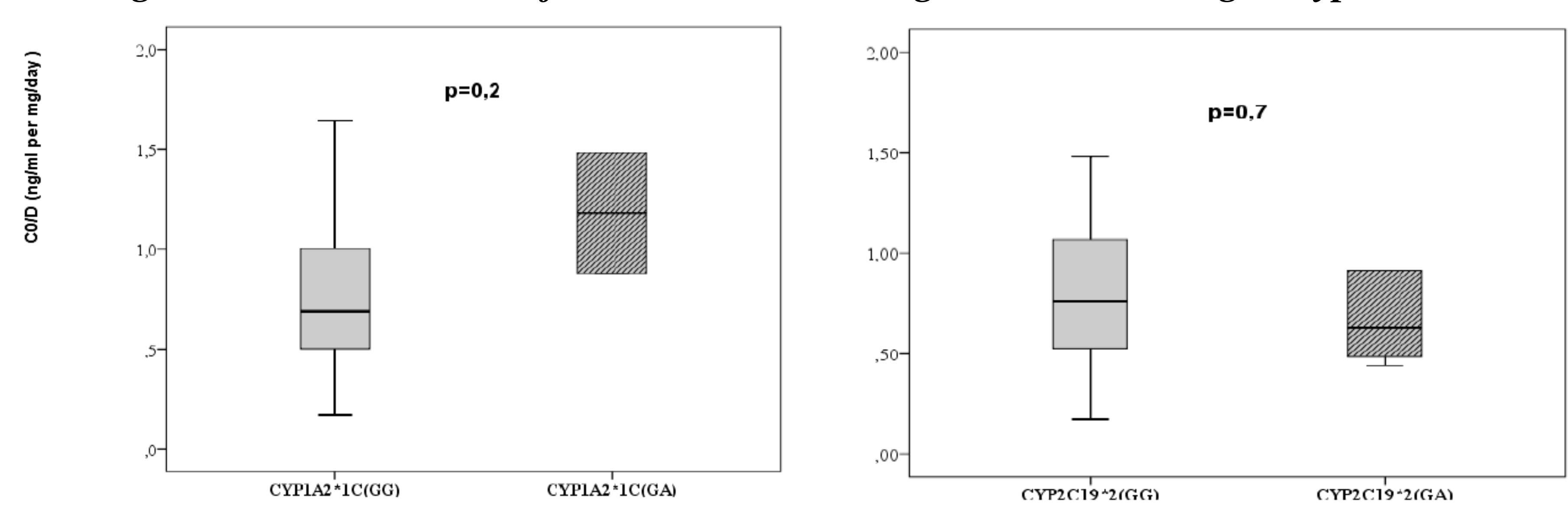

Figure 3 : The variation of C0/D ratio according to CYP1A2*1C genotypes \& $C Y P 2 C 19 * 2$ genotypes

* Influence of genotype combinations on pharmacokinetics of clozapine:

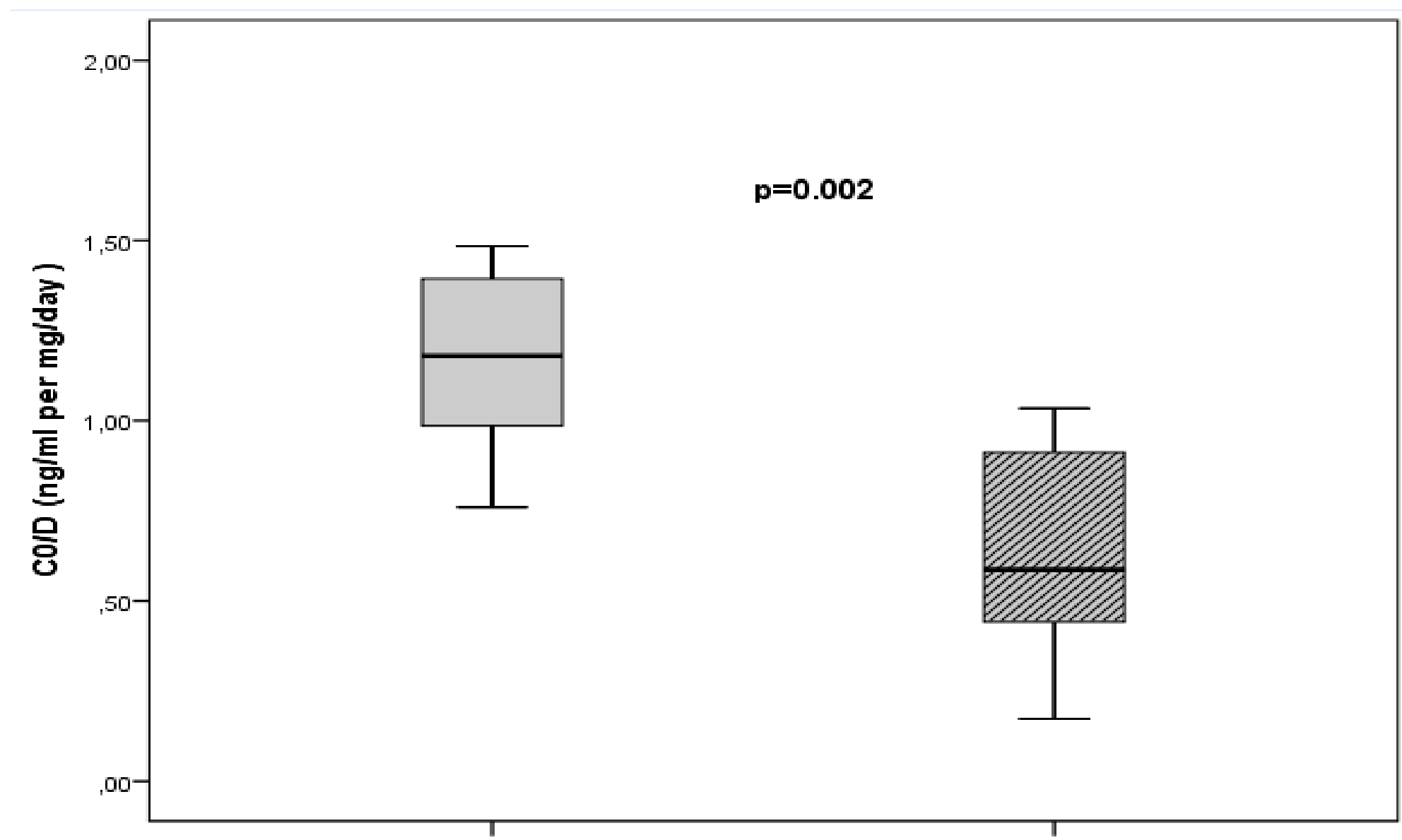

Figure 4 : The variation of CO/D ratio according to CYP1A2 Genotype combinations

* Univariate \& Multivariate analysis :

CYP1A2*1F :

- Univariate analysis : a significant correlation between the C0/D ratio of clozapine and CYP1A2* $1 \mathrm{~F}(\mathrm{p}=0,015)$

- Multivariate analysis : do not correlate with the C0/D variation

$>$ CYP1A2*1C \& CYP2C19*2 : absence of signicant correlation between these SNPs and the variability of C0/D.

$>$ Caffeine consumption : 17\% of clozapine PK variability.

\section{Discussion}

$>$ CYP2C19*2:

- The majority of studies ${ }^{2}$ : Influence on the $\mathrm{C} 0$ of clozapine

- Asian study ${ }^{3}$ : non-significant difference in C0/D between the genotypes of CYP2C19.

\section{Conclusion}

First study in the south Mediterranean population : the influence of the $C Y P 1 A 2$ and $C Y P 2 C 19$ genotype on pharmacokinetics of clozapine

* 3 SNPs studied : No influence

$>$ Inclusion of more patients \& others SNPs / genes : CYP1A2*1D, CYP2C19*17 / CYP2D6

$>$ Better to study the role of pharmacognetic on the TDM of clozapine in Tunisian patients. 